\title{
Low Doses of $17 \beta$-Estradiol Rapidly Improve Learning and Increase Hippocampal Dendritic Spines
}

\author{
Anna Phan', Christopher S Gabor ${ }^{1,2}$, Kayla J Favaro², Shayna Kaschack ${ }^{3}$, John N Armstrong 4 , \\ Neil J MacLusky ${ }^{2}$ and Elena Choleris*,I \\ 'Department of Psychology, University of Guelph, Guelph, Ontario, Canada; '2Department of Biomedical Sciences, University of Guelph, Guelph, \\ Ontario, Canada; ${ }^{3}$ Department of Biological Science, University of Guelph, Guelph, Ontario, Canada; ${ }^{4}$ Department of Molecular and Cellular \\ Biology, University of Guelph, Guelph, Ontario, Canada
}

\begin{abstract}
While a great deal of research has been performed on the long-term genomic actions of estrogens, their rapid effects and implications for learning and memory are less well characterized. The often conflicting results of estrogenic effects on learning and memory may be due to complex and little understood interactions between genomic and rapid effects. Here, we investigated the effects of low, physiologically relevant, doses of $17 \beta$-estradiol on three different learning paradigms that assess social and non-social aspects of recognition memory and spatial memory, during a transcription independent period of memory maintenance. Ovariectomized female CDI mice were subcutaneously administered vehicle, $1.5 \mu \mathrm{g} / \mathrm{kg}, 2 \mu \mathrm{g} / \mathrm{kg}$, or $3 \mu \mathrm{g} / \mathrm{kg}$ of $17 \beta$-estradiol 15 minutes before social recognition, object recognition, or object placement learning. These paradigms were designed to allow the testing of learning effects within 40 min of hormone administration. In addition, using a different set of ovariectomized mice, we examined the rapid effects of I.5 $\mu \mathrm{g} / \mathrm{kg}$, $2 \mu \mathrm{g} / \mathrm{kg}$, or $3 \mu \mathrm{g} / \mathrm{kg}$ of $17 \beta$-estradiol on CAI hippocampal dendritic spines. All $17 \beta$-estradiol doses tested impacted learning, memory, and CAI hippocampal spines. $17 \beta$-Estradiol improved both social and object recognition, and may facilitate object placement learning and memory. In addition, I7 $\beta$-estradiol increased dendritic spine density in the stratum radiatum subregion of the CAI hippocampus, but did not affect dendritic spines in the lacunosum-moleculare, within $40 \mathrm{~min}$ of administration. These results demonstrate that the rapid actions of $17 \beta$-estradiol have important implications for general learning and memory processes that are not specific for a particular type of learning paradigm. These effects may be mediated by the rapid formation of new dendritic spines in the hippocampus.
\end{abstract} Neuropsychopharmacology (2012) 37, 2299-2309; doi:I0.1038/npp.2012.82; published online 6 June 2012

Keywords: estrogens; PPT; DPN; learning and memory; discrimination; hippocampus

\section{INTRODUCTION}

Estrogens have a variety of effects on the central nervous system, which typically require hours or even days to take effect (see Nilsson et al, 2001) and are likely mediated through transcriptionally regulated changes in gene expression. Recently, it has been shown that estrogens affect cell signaling molecules, neuronal excitability, and behavior as rapidly as $15 \mathrm{~min}$ after administration (reviewed in Woolley, 2007; Vasudevan and Pfaff, 2008). These rapid effects are less well characterized than the genomic effects, but they may combine to produce complex results, which may help explain how estrogens often yield conflicting results for

\footnotetext{
*Correspondence: Professor E Choleris, Department of Psychology, University of Guelph, MacKinnon Building Room 3004, Guelph, Ontario, Canada NIG 2WI, Tel: + I $5198244120 \times 52729$, Fax: + I 519837 8629, E-mail: echoleri@uoguelph.ca Received 16 December 201 I; revised 24 April 2012; accepted 25 April 2012
}

learning and memory ranging from impairment to improvement (reviewed in Choleris et al, 2008). However, our knowledge about the implications of estrogenic rapid actions for learning and memory is still very limited.

Estrogens affect some behaviors as little as $15-35 \mathrm{~min}$ after administration a timing consistent with their nongenomic effects, on neuronal electrophysiology and cell signaling cascades. $17 \beta$-Estradiol administered to males of several species increased sexual behavior and aggression within this short time interval (Cross and Roselli, 1999; Cornil et al, 2006; Trainor et al, 2008; Charlier et al, 2010). A few studies attempted to examine estrogen's rapid effects on memory consolidation. Administration of $17 \beta$ - and $17 \alpha-$ estradiol immediately (but not $45 \mathrm{~min}$ or $2 \mathrm{~h}$ ) after learning acquisition in an object recognition and spatial learning task improved performance $4-48 \mathrm{~h}$ later, supporting a facilitatory role for estrogens on memory consolidation (Luine et al, 2003; Walf et al, 2008; Inagaki et al, 2010; Gresack and Frick, 2006; Fernandez et al, 2008; Fan et al, 2010). 
Recently, we demonstrated for the first time that estrogen receptor (ER) $\alpha$ and $\operatorname{ER} \beta$ agonists rapidly affect learning acquisition and hippocampal dendritic spine density within $40 \mathrm{~min}$ of systemic administration (Phan et al, 2011). Activation of ER $\alpha$ enhanced social recognition, object recognition, and object placement learning. This was consistent with increases in dendritic spine density in the CA1 area of the hippocampus in mice that had not been tested on the learning protocols (Phan et al, 2011). The selective $\mathrm{ER} \beta$ agonist facilitated object placement learning and impaired social recognition at higher doses, but failed to improve or impair object recognition learning, and either failed to affect CA1 spine density or decreased it (Phan et al, 2011). However, since behaviors mediated by ER $\alpha$ and $\operatorname{ER} \beta$ vary widely (Phan et al, 2011; Choleris et al, 2008), it is not clear whether $17 \beta$-estradiol, which binds equally to $\mathrm{ER} \alpha$ and $\operatorname{ER} \beta$, would affect learning within the same rapid time frame.

In this study, we used three different spontaneous learning paradigms to examine the rapid effects of $17 \beta$ estradiol. We previously used these paradigms to study the rapid effects of $\mathrm{ER} \alpha$ and $\mathrm{ER} \beta$ agonists (Phan et al, 2011). They do not require extensive training and can be completed 15-40 min after hormone treatment. Using these learning paradigms, we examined the rapid effects of estradiol when memories are transcriptionally independent (Nguyen et al, 1994; Bourtchuladze et al, 1994; Da Silva et al, 2008). They also allow us to assess estrogen's effects on three different learning systems for which their underlying neuroanatomical mechanisms are not completely independent (Dere et al, 2007; Broadbent et al, 2004; Petrulis, 2009). We used low dosages of $17 \beta$-estradiol, $1.5 \mu \mathrm{g} / \mathrm{kg}, 2 \mu \mathrm{g} / \mathrm{kg}$, and $3 \mu \mathrm{g} / \mathrm{kg}$ within a physiological range, since rapid estrogen effects are frequently reported for doses higher than required for their genomic effects, questioning whether these effects are biologically meaningful (eg, 100 fold higher in some electrophysiology experiments; reviewed in Woolley, 2007). The range of doses we used was chosen to be physiologically relevant (Iizuka et al, 1998; Scharfman et al, 2007). The highest dose, $3 \mu \mathrm{g} / \mathrm{kg}$, produced levels of plasma estradiol in ovariectomized rats corresponding to proestrus levels when estrogens naturally peak (Scharfman et al, 2007).

Estrogen treatment also increases hippocampal dendritic spine density as quickly as $15-30 \mathrm{~min}$ after hormone application (MacLusky et al, 2005; Mukai et al, 2007; Murakami et al, 2006; Srivastava et al, 2008). However, to the best of our knowledge, it is not known whether rapidly induced spine changes correspond with any behavioral learning and memory effects. Moreover, since ER $\alpha$ and $\operatorname{ER} \beta$ agonists rapidly affect mouse hippocampal dendritic spines in opposing directions (Phan et al, 2011), how 17 $\beta$-estradiol will affect mouse hippocampal spines at this time scale is uncertain. Therefore, in addition to $17 \beta$-estradiol's rapid effects on learning and memory, we also analyzed their rapid effects on dendritic spines within the CA1 area of the hippocampus.

\section{MATERIALS AND METHODS}

\section{Subjects}

In all, 185 female CD1 mice (Mus musculus) were purchased (2 months old; Charles River, Saint-Constant, QC, Canada) and ovariectomized. Nine animals were randomly chosen as stimulus animals for social recognition experiments, 138 subjects were tested in behavioral learning paradigms, 18 subjects were tested for olfaction, and 20 mice were used to investigate $17 \beta$-estradiol effects on hippocampal dendritic spines. Mice were housed on a reversed light/dark cycle $(12: 12 \mathrm{~h}$, lights on at $2000 \mathrm{~h})$ at $21 \pm 1^{\circ} \mathrm{C}$. Subjects were held in clear polyethylene cages $\left(26 \times 16 \times 12 \mathrm{~cm}^{3}\right)$ with corncob bedding, environmental enrichment (paper nesting material and paper cup), and rodent chow (14\% Protein Rodent Maintenance Diet, Harlan Teklad, WI) and tap water ad libitum. Experimental mice were individually housed and cages were not cleaned for at least 3 days before testing to establish a home cage territory. Stimulus mice were group housed. All behavioral paradigms were conducted in home cage under red light, during the dark phase of their light cycle.

The evening before testing, experimental mice were moved into the testing room to acclimate, body weights and vaginal smears were taken. To ensure effective ovariectomies, vaginal cells were stained with Giemsa (Sigma-Aldrich, Oakville, ON, Canada). Cycling animals were removed from the data set (one animal). Test mice were only used in one experiment. Conducted in accordance with the Canadian Council on Animal Care and approved by University of Guelph's Animal Care and Use Committee.

\section{Ovariectomy Surgery}

All mice were ovariectomized as previously described in Clipperton Allen et al (2011). Briefly, mice were anaesthetized using isoflurane, subcutaneously (s.c.) injected with an analgesic and anti-inflammatory $(50 \mathrm{mg} / \mathrm{kg}$ Rimadyl, Pfizer Canada, Kirkland, QC, Canada). One dorsal incision was made in the skin, then ovaries were removed through two incisions in the dorsal muscles. A surgical clip $(9 \mathrm{~mm}$ wound clips, MikRon Precision, Gardena, CA) was used to close the incision. Experiments were performed 10-15 days after surgery.

\section{Rapid Learning Paradigms}

Animals were injected s.c. with $1.5 \mu \mathrm{g} / \mathrm{kg}, 2 \mu \mathrm{g} / \mathrm{kg}$, or $3 \mu \mathrm{g} / \mathrm{kg}$ of $17 \beta$-estradiol (Sigma-Aldrich) or sesame oil (vehicle control) at a volume of $10 \mathrm{~mL} / \mathrm{kg}$. The dose range was chosen to mimic levels of estradiol observed in the proestrous (highest dose), estrous, and diestrous phases of the estrous cycle. The lowest dose was half of the highest dose, and a middle dose was included between the two, which is comparable to the range of ER agonists we used previously (Phan et al, 2011). In ovariectomized rats, the highest dose, $3 \mu \mathrm{g} / \mathrm{kg}$, resulted in plasma estradiol levels in the proestrus range (Scharfman et al, 2007). Our choice of doses is based on the rat literature (Scharfman et al, 2007), since the mouse literature is limited, likely due to the challenges in accurately measuring estradiol in small volumes of plasma (Haisenleder et al, 2011). However, in the classic uterotrophic assay, comparable responsiveness was shown in rats and mice to the same dose (per body weight) of estradiol (Padilla-Banks et al, 2001; Harris et al, 2008; Peano et al, 2009). In addition, s.c., injections of $3 \mu \mathrm{g} / \mathrm{kg}$ of $17 \beta$-estradiol to ovariectomized mice restored uterine 
weight to that of sham-operated mice (Iizuka et al, 1998). Hence, it is likely that the doses we chose fall within the physiological range in mice as they do in rats (Scharfman et al, 2007). Higher doses of $10 \mu \mathrm{g} / \mathrm{kg}$ and above resulted in uterine weight increases beyond the sham-operated control mice, and it produced supraphysiological levels of plasma estradiol in ovariectomized rats (Iizuka et al, 1998; MacLusky et al, 2005; Scharfman et al, 2007).

Drug treatments were assigned using a random number generator. The injection site was sealed with superglue (instant Krazy glue, Elmer's Products Canada, Toronto, ON) to prevent leakage. Mice were injected $15 \mathrm{~min}$ before testing. Each learning paradigm was completed within $40 \mathrm{~min}$ of drug administration, targeting $17 \beta$-estradiol's rapid effects. Learning paradigms consisted of two habituation sessions and a test, each $5 \mathrm{~min}$ in duration, separated by $5 \mathrm{~min}$ intervals (previously described in Phan et al, 2011). These learning paradigms were designed such that vehicle controls do not demonstrate learning, to test for improving effects of $17 \beta$-estradiol. When given greater numbers of habituations, vehicle-treated control mice successfully perform these tasks (see Phan et al, 2011).

Habituation and test sessions were recorded under infrared light $(8 \mathrm{~mm}$ Handycam Nightshot, Sony, Cambridge, ON, Canada) for ethological analysis. During all intertest intervals, objects and cylinders used to present stimulus mice (described below) were washed using an odorless detergent and baking soda to remove odor cues. Objects were held in place using Velcro, and were tested to ensure mice showed no preference for one object. Objects used: glass cube $\left(4 \times 4 \times 4 \mathrm{~cm}^{3}\right)$, stainless steel drain catcher $\left(6 \times 6 \times 1 \mathrm{~cm}^{3}\right)$, and plastic hairclip $\left(4 \times 3 \times 3 \mathrm{~cm}^{3}\right)$.

\section{Social Recognition Paradigm}

Ovariectomized female CD1 stimulus mice 2.5-4 months old were presented to experimental mice in clear Plexiglas cylinders with perforations at the bottom, to allow passage of olfactory cues (as described in Choleris et al, 2006). During habituations, a test mouse was presented with the same two stimulus mice (eg, A and B) in consistent positions. During test, one of the two stimulus mice was replaced with a novel mouse (eg, A and C). The individual replaced was counterbalanced.

\section{Object Recognition Paradigm}

During habituation sessions, two different objects were presented to the test mouse in consistent positions, while during test, one of the two objects was replaced with a novel third object. The object that was replaced was counterbalanced, and the two positions of the objects remained consistent throughout the paradigm.

\section{Object Placement Paradigm}

Two identical objects were placed in two out of four possible locations within home cage, and these two locations were consistent during habituations. During test, one of the objects was moved $12-14 \mathrm{~cm}$ to a novel location, directly across from the original placement of the object. The object moved was counterbalanced.

\section{Behavioral Data Analysis}

Specific numbers of mice used for behavioral learning paradigms are recorded in figure legends for investigation durations (Figure $1 \mathrm{~b}, \mathrm{~d}$, and $\mathrm{f}$ ). Ten behaviors (Table 1) were collected during the paradigms using The Observer Video Analysis software (Noldus Information Technology, Wageningen, Netherlands) by three observers blind to drug treatment.

Investigation behavior was considered active sniffing of stimuli, nose twitching and within $\sim 1-2 \mathrm{~mm}$ of the stimulus. Exploiting the natural tendency of mice to investigate novel stimuli or displaced stimuli more than familiar ones, we calculated an investigation percent. Percent investigation $=N /(N+F) \times 100$, where $N$ is the time a test mouse spends investigating the novel or displaced stimulus (or during habituations, the stimulus that will be replaced/displaced) and $F$ is the time spent investigating the familiar stimulus. Investigation percent during habituations typically fluctuates around 50\% (chance), while during test, if the experimental mice recognize the novel or displaced stimulus, investigation percent is statistically greater than during habituation (ie, $>50 \%$; Phan et al, 2011). Investigation percent at habituation 1 and 2 were averaged to minimize ambiguity and errors that may result due to small random fluctuations in mice investigative behavior. Animals with total investigation durations of $<5 \mathrm{~s}$ during test ( $3 \%$ of animals) as well as outliers ( $>2$ SDs \pm mean; $2 \%$ of animals) were excluded.

\section{Olfaction Test}

Mice were food deprived and weighed the evening before testing, then given one Hershey's chocolate chip ( $\sim 250-$ $300 \mathrm{mg}$ ) to familiarize them with the food item. To determine whether learning enhancements could have resulted from changes in olfactory capabilities, mice were injected with vehicle $(n=8)$ or $3 \mu \mathrm{g} / \mathrm{kg} \quad 17 \beta$-estradiol $(n=10)$. Forty minutes after injection, $\frac{1}{4}$ of a Hershey's chocolate chip ( $\sim 70-80 \mathrm{mg}$ ) was buried in the bedding while the experimenter gently tapped the bedding to draw the mouse away from the burial site. The latency for the mice to find the chocolate chip was recorded.

\section{Dendritic Spine Analysis}

Twenty experimentally naïve ovariectomized CD1 females were injected s.c. with $1.5 \mu \mathrm{g} / \mathrm{kg}, 2 \mu \mathrm{g} / \mathrm{kg}, 3 \mu \mathrm{g} / \mathrm{kg}$ of $17 \beta$ estradiol or vehicle (five animals/group) as described above, returned to home cage, and were euthanized $40 \mathrm{~min}$ later using $\mathrm{CO}_{2}$ (as per animal care guidelines). The brain extractions were performed as quickly as possible $(1 \mathrm{~min}$ on average) to limit $\mathrm{CO}_{2}$ effects on cytoarchitecture. Methods are described in detail in Phan et al, 2011. Briefly, brains were placed in Golgi-Cox solution (1\% potassium dichromate, $0.8 \%$ potassium monochromate, $1 \%$ mercuric chloride) for 3 weeks in the dark, then in $20 \%$ sucrose phosphate buffer $(\mathrm{PB})\left(48 \mathrm{~h}\right.$ at $\left.4{ }^{\circ} \mathrm{C}\right)$. The brains were sectioned using a vibrating microtome (Leica VT1000x, Leica Microsystems, Richmond Hill, ON, Canada) at $200 \mu \mathrm{m}$. Free floating sections were stored in $6 \%$ sucrose $\mathrm{PB}\left(24 \mathrm{~h}\right.$ at $\left.4^{\circ} \mathrm{C}\right)$, then processed in $4 \%$ paraformaldehyde $(15 \mathrm{~min}), 1 \% \mathrm{NH}_{4} \mathrm{OH}$ 

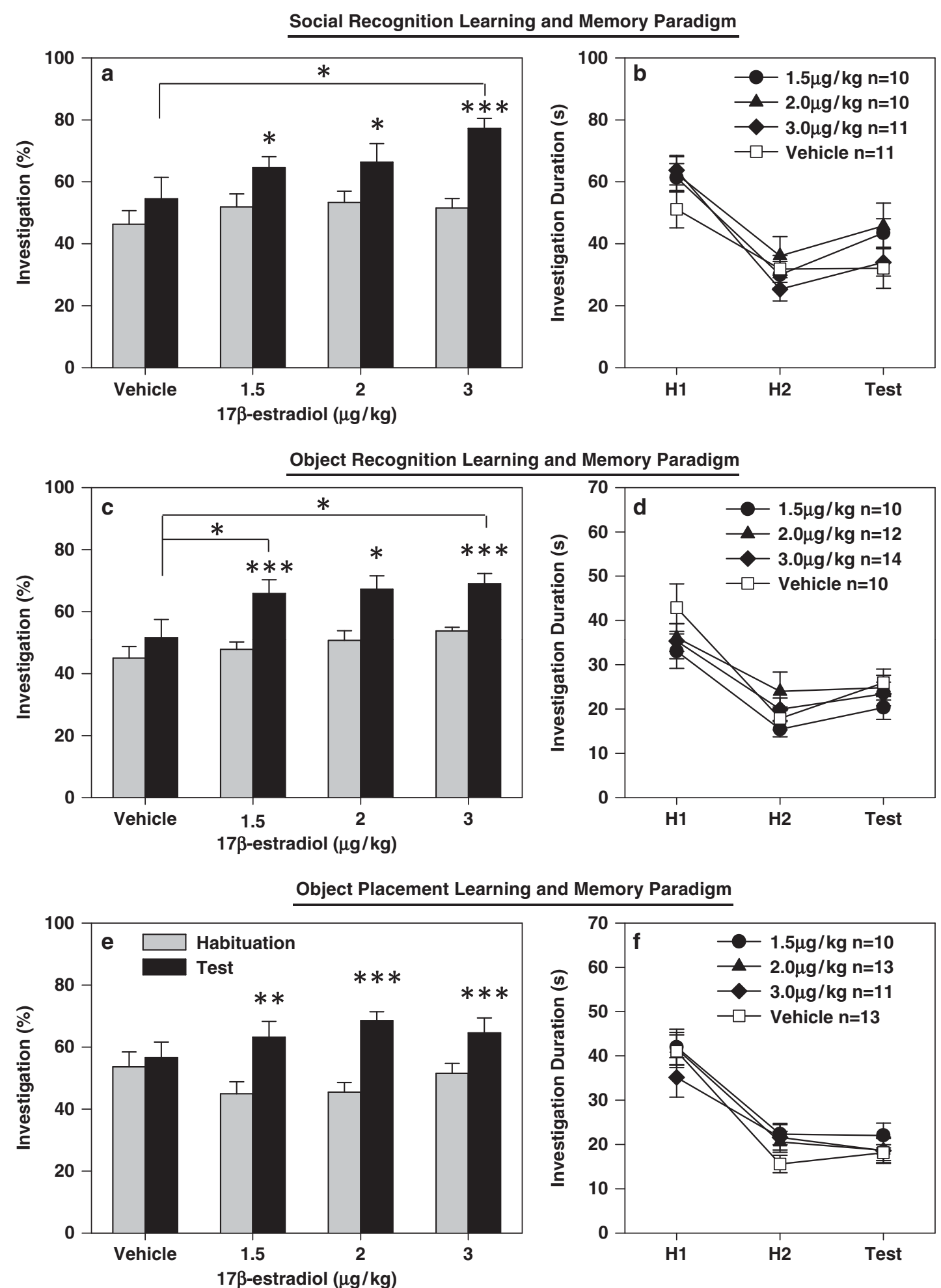

Figure I Rapid effects of $17 \beta$-estradiol on learning and memory paradigms. Bar graphs illustrate investigation percent (gray bars average habituation, black bars test investigation percent). Line graphs illustrate total investigation durations ( $\mathrm{H}$ indicates habituation). (a) $3.0 \mu \mathrm{g} / \mathrm{kg}$ of $17 \beta$-estradiol improved social recognition above vehicle controls, and all groups administered $17 \beta$-estradiol successfully demonstrated social recognition. (b) Total mouse investigation durations were not affected by $17 \beta$-estradiol treatment. (c) 1.5 and $3.0 \mu \mathrm{g} / \mathrm{kg}$ of $17 \beta$-estradiol improved object recognition above vehicle controls, and all groups administered $17 \beta$-estradiol successfully demonstrated novel object discrimination. (d) Total object investigation durations were unaffected by I7 $\beta$ estradiol treatment. (e) All groups administered $17 \beta$-estradiol successfully demonstrated novel object location discrimination, in the object placement paradigm. (f) I $7 \beta$-Estradiol treatment did not affect total object investigation durations. Asterisks above black bars indicate a significant difference between habituation and test within treatment group. Mean \pm SEM $* p<0.05$, ** $p<0.01, * * * p<0.001$. 
Table I A List and Description of the Behaviors Collected and Analyzed for Learning Paradigms

\begin{tabular}{ll}
\hline Behavior & Description \\
\hline Sniff stimulus & Sniffing of object or mouse stimulus. Nose twitching and within I-2 mm of stimuli \\
Bite stimulus & Biting object or mouse stimulus cylinders \\
Sit/climb on stimulus & Sitting/climbing on object stimulus with all four paws off the cage floor \\
Dig & Movement of forepaws propelling bedding in posterior direction \\
Bury & Movement of forepaws pushing bedding away from body in anterior direction \\
Horizontal exploration & Walking, non-stimulus sniffing and exploration of cage \\
Rearing & Both forepaws off the cage floor \\
Self-groom & Grooming with forepaws moving over face and body \\
Inactivity & Includes behaviors such as sit, lay down, freeze, and sleep \\
Stereotypy & Strange, repetitive behaviors (>3 repetitions), such as jumps, head shakes, lid chews, etc. \\
\hline
\end{tabular}
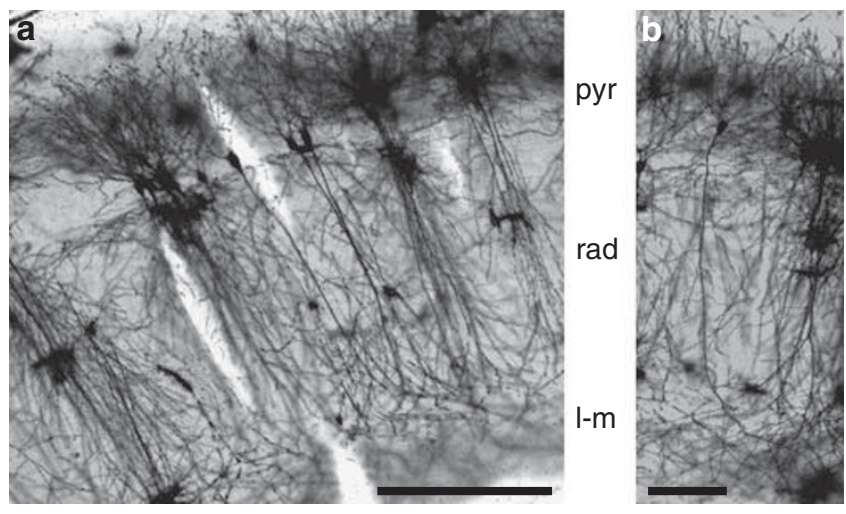

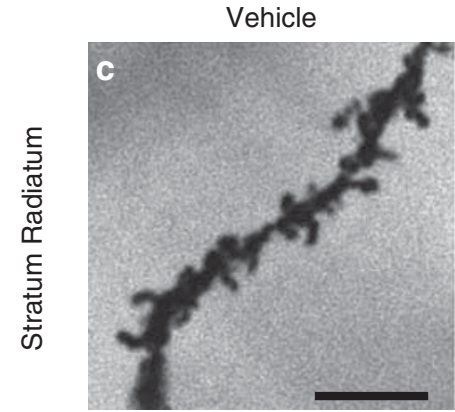

Vehicle

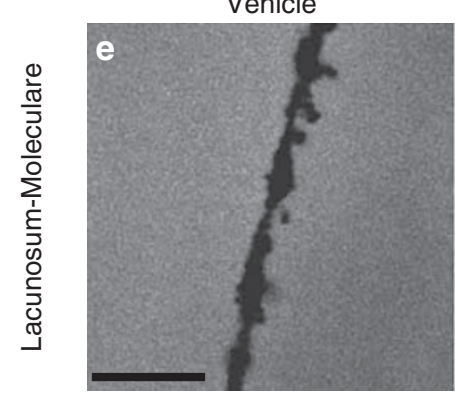

Figure 2 Images of Golgi-Cox-stained hippocampal CAI neurons. Pyr, pyramidal cell layer; rad, stratum radiatum; I-m, lacunosum-moleculare. (a) Scale bar $200 \mu \mathrm{m}$. (b) Scale bar $100 \mu \mathrm{m}$. (c-f) Images of secondary dendrites from CAI pyramidal neurons, from the stratum radiatum and lacunosum-moleculare of female mice treated with vehicle, 2.0 or $3.0 \mu \mathrm{g} / \mathrm{kg}$ of $17 \beta$-estradiol. Scale bars $5 \mu \mathrm{m}$.
(15 $\mathrm{min}), 1 \%$ Kodak rapid fixative $(15-60 \mathrm{~min})$. Sections mounted on gelatin-coated slides were air dried $(1.5-2 \mathrm{~h})$ and coverslipped.

Images from the stratum radiatum and lacunosummoleculare subregions of the CA1 hippocampus (Figure 2) were taken $(\times 63$ oil objective microscope, Axio Imager D1, captured with AxioCam MRc5 digital camera using AxioVision 4.6 software, Carl Zeiss, Toronto, ON, Canada). An observer blind to treatments analyzed images of five neurons from each animal using Image $\mathrm{J}$ software (version 1.38x, National Institutes of Health, Bethesda, MD). The sampling region was $30-50 \%$ (stratum radiatum) and $80-100 \%$ (lacunosum-moleculare) the length of the apical dendrite, from $>10 \mu \mathrm{m}$ of dendrite length. Dendritic spine density (spines per $10 \mu \mathrm{m}$ ) and spine length (distal tip of spine head to edge of dendrite) was measured from two secondary dendrites in each of the stratum radiatum and lacunosummoleculare of the same neuron. These measures were averaged per subregion for every neuron, then an average value was calculated from the five neurons for each mouse.

\section{Statistical Analysis}

Investigation percent for habituation 1 and 2 were averaged for analysis. Two-way repeated measures ANOVAs were used to analyze behavioral data, with habituation and test as the repeated measure, and treatment as a between groups factor. To reduce type I errors, specific a priori binary mean comparisons were planned in the statistical model to assess the effects of the change in experimental condition at test (novel stimulus/location). Specifically, within the ANOVA model paired $t$-tests were used to assess differences in preference scores between habituation and test within each treatment group, and one-way ANOVAs and StudentNeuman-Keuls (SNK) post hocs were used to assess differences in preference scores at test between doses. Data for preference scores (expressed as a ratio) were arcsin transformed. Dendritic spine data were analyzed using Kruskal-Wallis ANOVA on ranks, and SNK post hocs. Sigmastat version 3.5 was used for all statistical analyses (Systat Software, Chicago, IL). Statistical significance was 
set at $p<0.05$. For brevity, non-significant values/results are not presented unless meaningful.

\section{RESULTS}

\section{Learning Paradigms}

Social recognition. 17 $\beta$-Estradiol rapidly improved social recognition (Figure 1a). The ANOVA for percent investigation during test indicated a significant main effect of treatment $\left(\mathrm{F}_{3,38}=3.379, p<0.05\right)$. Post hoc analysis indicated that the $3 \mu \mathrm{g} / \mathrm{kg} 17 \beta$-estradiol group had a significantly higher percent investigation at test compared with vehicle $(q=4.476, d f=20, p<0.05)$. Furthermore, investigation percent at test was significantly higher than at habituation for all groups treated with $17 \beta$-estradiol but not for the vehicle control group (vehicle: $t=1.13, \mathrm{df}=10$, N.S., $1.5 \mu \mathrm{g} / \mathrm{kg}: t=2.49, d f=9, p<0.05,2 \mu \mathrm{g} / \mathrm{kg}: t=2.63$, $d f=9, p<0.05,3 \mu \mathrm{g} / \mathrm{kg}: t=5.40, d f=10, p<0.001)$. This indicates that all groups administered the steroid hormone were able to demonstrate social recognition, whereas the vehicle-treated mice could not.

Total social investigation times (amount of time spent sniffing both stimulus animals) were not significantly different between treatment groups, and mice demonstrated normal habituation to stimulus animals (Figure 1b). Total investigation duration differed significantly across habituations and test $\left(\mathrm{F}_{2,76}=41.161, p<0.001\right)$, and post hoc tests indicated significant decreases in investigation from habituation 1 to habituation 2 and from habituation 1 to test (all $q>3.69$, all $p<0.025$ ). In addition, there was a significant interaction for treatment across test number for inactivity $\left(\mathrm{F}_{6,76}=2.80, p<0.05\right)$ and rearing duration $\left(\mathrm{F}_{6,76}=2.53\right.$, $p<0.05)$. Post hoc analyses revealed a significant increase in inactivity duration from habituation 1 to 2 in the $3 \mu \mathrm{g} / \mathrm{kg}$ $17 \beta$-estradiol group $(q=3.54, d f=10, p<0.05)$, but no differences between treatment groups. Rearing duration was significantly higher during habituation 1 compared with habituation 2 and test within the $3 \mu \mathrm{g} / \mathrm{kg} 17 \beta$-estradiol group $(q=6.66, d f=10, \quad p<0.001, q=6.23, d f=10$, $p<0.001$, respectively). During habituation 1 , the $3 \mu \mathrm{g} / \mathrm{kg}$ $17 \beta$-estradiol group also had higher rearing durations compared with vehicle $(q=5.17, d f=20, p<0.01)$. There were no other effects of $17 \beta$-estradiol treatment on other behaviors analyzed, suggesting that learning and memory enhancements were not due to changes in overall activity.

Object recognition. Treatment with $17 \beta$-estradiol rapidly improved object recognition in mice (Figure 1c). A one-way ANOVA revealed a significant main effect of treatment for percent investigation during test $\left(\mathrm{F}_{3,44}=2.93, p<0.05\right)$. Post hoc analysis revealed that animals treated with 1.5 and $3 \mu \mathrm{g} / \mathrm{kg}$ of $17 \beta$-estradiol had significantly higher test percent investigation values compared with vehicle animals $(1.5 \mu \mathrm{g} /$ $\mathrm{kg}: q=3.09, d f=20, p<0.05,3 \mu \mathrm{g} / \mathrm{kg}: q=3.86, d f=22$, $p<0.05)$. In addition, investigation percent at test was significantly higher than at habituation for all groups treated with $17 \beta$-estradiol, indicating they were all able to successfully perform the task, whereas the vehicle control group could not (vehicle: $t=1.21, d f=9$, N.S., $1.5 \mu \mathrm{g} / \mathrm{kg}$ : $t=4.29, \quad d f=11, \quad p=0.001, \quad 2 \mu \mathrm{g} / \mathrm{kg}: \quad t=2.46, \quad d f=11$, $p<0.05,3 \mu \mathrm{g} / \mathrm{kg}: t=4.21, d f=13, p=0.001)$.
Similar to the results found with social recognition, total object investigation was significantly different across test numbers, indicative of normal habituation of mice to the objects $\left(\mathrm{F}_{2,88}=45.302, p<0.001\right.$; Figure $\left.1 \mathrm{~d}\right)$. Habituation 1 total investigation durations were significantly higher than that of habituation 2 and of test (all $q>4.19$, all $p<0.01$ ). There was no effect of treatment on any other behavior analyzed, suggesting that $17 \beta$-estradiol's effects on object recognition were not secondary to changes in other behaviors.

Object Placement. 17 $\beta$-Estradiol may have rapidly facilitated object placement, since all groups of animals receiving the hormone demonstrated successful discrimination of the displaced object, while the vehicle control did not (Figure 1e). Planned comparisons indicate significantly higher investigation percent values during test compared with habituation in estradiol-treated groups (vehicle: $t=1.99, d f=12$, N.S., $1.5 \mu \mathrm{g} / \mathrm{kg}$ using Wilcoxon signed rank test: $Z=2.70, d f=9, p<0.01,2 \mu \mathrm{g} / \mathrm{kg}: t=4.44, d f=12$, $p<0.001,3 \mu \mathrm{g} / \mathrm{kg}: t=4.46, d f=10, p=0.001)$.

While treatment did not affect total object investigation durations, we found that total investigation durations were significantly different across test number $\left(\mathrm{F}_{2,86}=62.18\right.$, $p<0.001$; Figure 1f). Mice habituated to the stimuli, since investigation durations at habituation 1 were significantly higher compared with habituation 2 and compared with test (all $q>4.44$, all $p<0.025$ ). There was no significant effect of treatment on any other behavior analyzed, suggesting that effects of $17 \beta$-estradiol were specific to object placement performance.

Olfaction Test. Administration of $3 \mu \mathrm{g} / \mathrm{kg}$ of $17 \beta$-estradiol did not rapidly affect the latency of mice to find a buried chocolate chip $(p=0.74$, vehicle $16.5 \pm 5.8 \mathrm{~s}, 3 \mu \mathrm{g} / \mathrm{kg} 14.3 \pm$ $3.5 \mathrm{~s}$, mean \pm SEM). Thus, $17 \beta$-estradiol learning and memory effects are not secondary to improved olfaction in treated animals.

\section{Dendritic Spines}

Hippocampal dendritic spines were rapidly changed with $17 \beta$-estradiol treatment (Figure 3). There was a significant main effect of treatment on spine density in the stratum radiatum (Spine density: $H=12.051, d f=3, p<0.01$ ). Post hoc analysis revealed estradiol at all doses significantly increased spine density in the stratum radiatum compared with vehicle $(1.5 \mu \mathrm{g} / \mathrm{kg}: q=4.46, d f=8, p<0.05,2 \mu \mathrm{g} / \mathrm{kg}$ : $q=5.61, d f=8, p<0.05,3 \mu \mathrm{g} / \mathrm{kg}: q=5.30, d f=8, p<0.05$; Figure $3 \mathrm{a}$ and $\mathrm{b}$ ). However, there was no effect of $17 \beta$ estradiol on spine length (Figure $3 c$ and $d$ ). Changes in spine density and length in the lacunosum-moleculare were not statistically significant (Figure 4).

\section{DISCUSSION}

\section{Rapid Effects of $17 \beta$-Estradiol on Learning}

Treatment with $17 \beta$-estradiol improved social recognition, object recognition, and may facilitate object placement performance $40 \mathrm{~min}$ after systemic administration (Figure la, c, and e). In all, $3 \mu \mathrm{g} / \mathrm{kg}$ of $17 \beta$-estradiol improved 

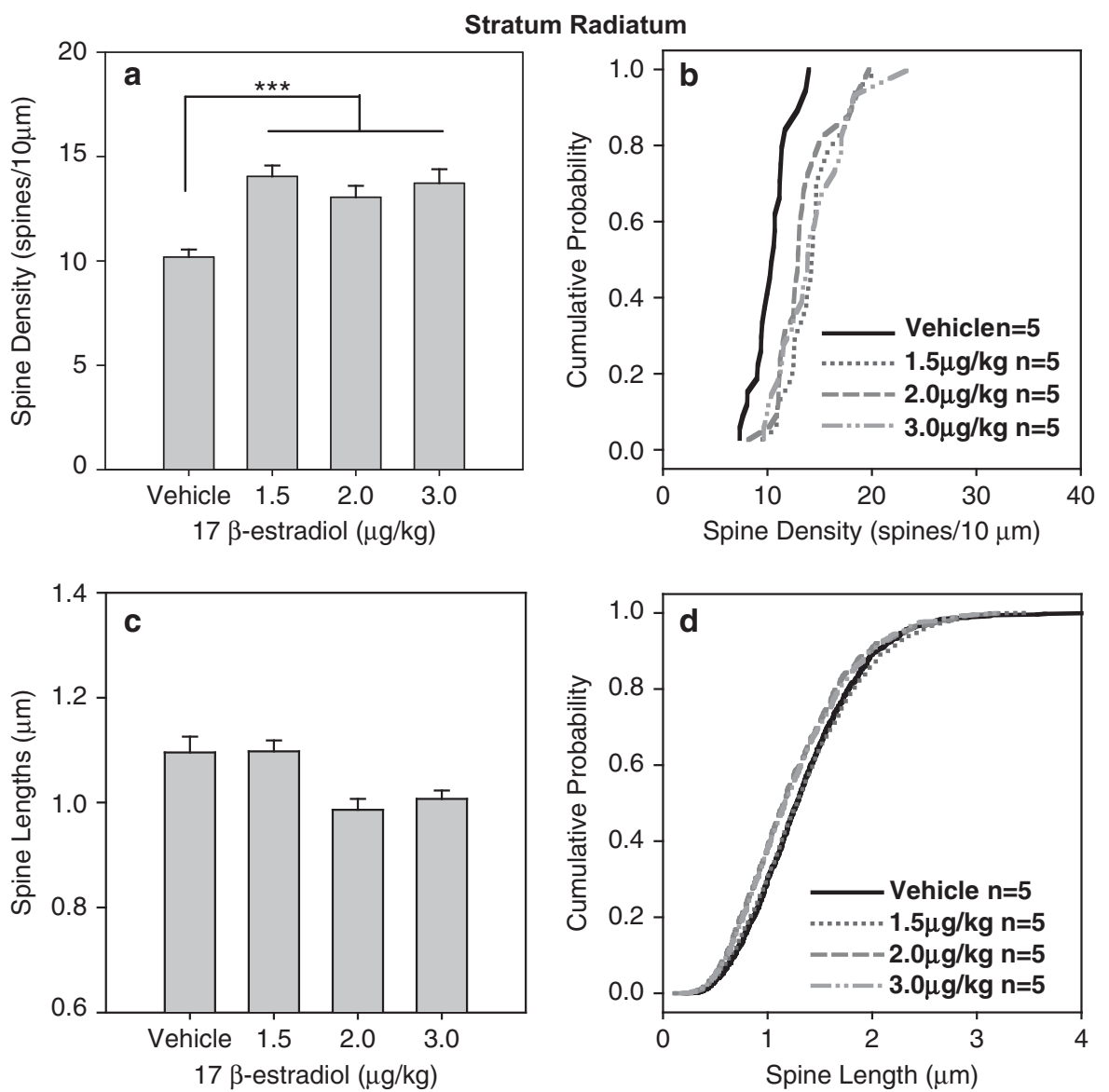

Figure 3 Rapid effects of $17 \beta$-estradiol on dendritic spines in the stratum radiatum of female mice. (a, b), Treatment with I.5, 2.0, or $3.0 \mu g / \mathrm{kg}$ of $17 \beta$-estradiol increased dendritic spine density compared with vehicle. (c, d), Treatment with $17 \beta$-estradiol did not affect spine length. Asterisks indicate a significant difference between vehicle and $17 \beta$-estradiol treatment groups. Mean + SEM. $* * * * p<0.001$.

social recognition, and 1.5 and $3 \mu \mathrm{g} / \mathrm{kg} \quad 17 \beta$-estradiol improved object recognition learning. For all paradigms tested, groups administered $17 \beta$-estradiol at any dose successfully completed the learning paradigms, while vehicle controls did not. These results suggest that $17 \beta$ estradiol rapidly facilitated learning and memory, and that the improvements seen may be on general learning and memory processes, since effects were not specific to one learning paradigm.

By and large, treatment with $17 \beta$-estradiol did not affect other behaviors recorded from these animals or their olfactory capabilities. Thus, the rapid effects of estrogens on learning and memory do not seem to be secondary to changes in other behaviors, such as overall activity. However, because we are testing the rapid effects of $17 \beta$ estradiol, we cannot methodologically eliminate the possibility that the rapid effects we observed in the three learning paradigms may be state-dependent, since serum estradiol has been shown to remain elevated at least $1-2 \mathrm{~h}$ after systemic injection in ovariectomized rats (Scharfman et al, 2007). In addition, because these learning paradigms depend on the response of test animals to novelty, apparent enhancements in performance can also be a product of increased interest in novelty per se. The fact that there were no drug treatment effects on total investigation durations in any learning paradigm tested during habituation 1 , when both stimuli were equally novel (Figure $1 b$, $d$, and $f$ ), suggests that the effects of estradiol in the three learning paradigms are likely not a result of enhanced interest in novelty. However, we cannot discount the possibility that this may occur at the $35 \mathrm{~min}$ post-hormone administration time point when the test was performed.

These rapid effects of $17 \beta$-estradiol are likely mediated by $\mathrm{ER} \alpha$, since we have previously shown that ER $\alpha$ agonist PPT rapidly improved performance in the social recognition, object recognition and object placement paradigms (Phan et al, 2011), in a manner similar to our current results with $17 \beta$-estradiol. In contrast, ER $\beta$ agonist DPN did not improve social or object recognition, but improved object placement performance only (Phan et al, 2011). However, unlike our studies with the ER agonists, the improved performance seen with $17 \beta$-estradiol appears more robust, since effects with ER agonists were very specific to one or two doses (out of four), while all groups receiving $17 \beta$ estradiol here were successful in the three learning paradigms and the vehicle-treated animals were not. This may indicate that either $\mathrm{ER} \alpha$ and $\operatorname{ER} \beta$ interact to produce a synergistic effect, or that other receptors such as the Gprotein coupled ER (GPER), or as yet other undefined ERs are involved in mediating this effect. Indeed, recent experiments from our laboratory indicate that a GPER agonist, G1, also rapidly improved social recognition, object 

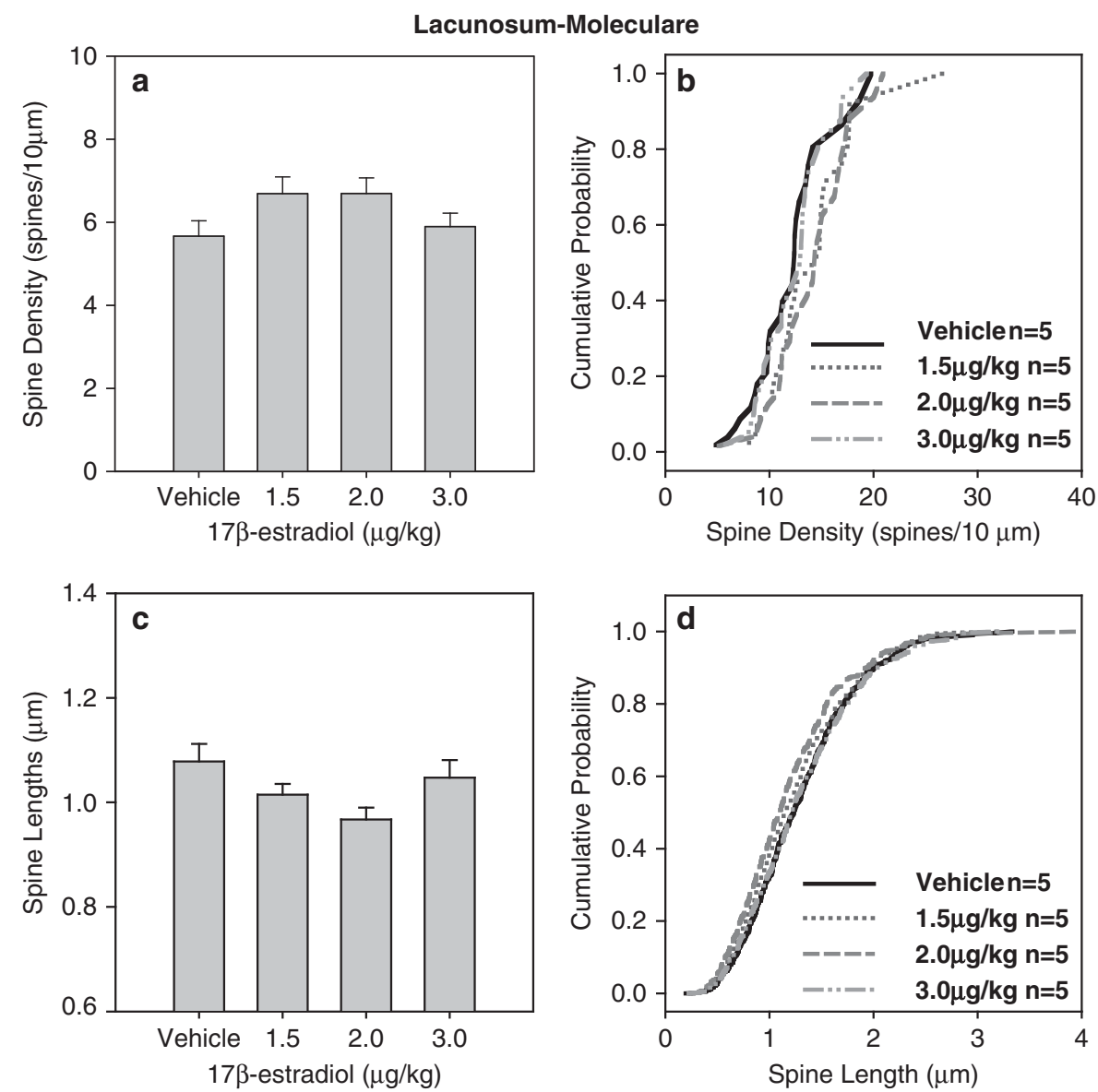

Figure 4 Rapid effects of $17 \beta$-estradiol on dendritic spines in the lacunosum-moleculare of female mice. Treatment with $17 \beta$-estradiol did not significantly affect dendritic spine density $(a, b)$ or dendritic spine length $(c, d)$. Mean + SEM.

recognition, and object placement performance (Gabor et al, 2011).

Estrogens rapidly affect several neuronal functions known to be important for learning and memory. For examples, $17 \beta$-estradiol rapidly affected glutamate receptor trafficking and transmission in neurons (Srivastava et al, 2008; Zhao and Brinton, 2007; Foy et al, 1999; Smejkalova and Woolley, 2010) and increased calcium influx (Zhao and Brinton, 2007; Zhao et al, 2005; Wu et al, 2005; Sarkar et al, 2008). Furthermore, or perhaps as a result of these effects, estrogen treatment increased activation of calcium-calmodulindependent protein kinase II (CaMKII) (Sawai et al, 2002) and the extracellular signal regulated kinase (ERK) signaling pathway (Fernandez et al, 2008; Fan et al, 2010; Srivastava et al, 2008; Zhao and Brinton, 2007; Smejkalova and Woolley, 2010; Lewis et al, 2008), both of which are activated by $\mathrm{Ca}^{2+}$ and critical for learning and memory and the expression of long-term potentiation (LTP) (Malinow et al, 1989; Thomas and Huganir, 2004). Lastly, estrogens rapidly facilitate hippocampal LTP (Foy et al, 1999; Zadran et al, 2009, but see Mukai et al, 2007) or long-term depression (Mukai et al, 2007). While there is a fair amount of evidence for estrogens affecting various signaling pathways and electrophysiological properties in neurons, the exact method through which estrogens are able to do so remains unclear. One possible way through which this may occur is estrogens action at L-type $\mathrm{Ca}^{2+}$ channels. Estrogens were found to potentiate neuronal L-type $\mathrm{Ca}^{2+}$ channels, leading to an increase in $\mathrm{Ca}^{2+}$ influx that apparently leads to activation of the ERK signaling pathway (Wu et al, 2005; Sarkar et al, 2008). Also, estrogens rapidly affect (or exert their effects through) various other signaling pathways, such as protein kinase A and phosphotidylinositol 3-kinase pathways (reviewed in Vasudevan and Pfaff, 2008; Kelly and Ronnekleiv, 2009). Whether these pathways might possibly be activated in a similar manner, that is, through enhanced neurotransmission or ion channel functions, is not well known.

\section{Rapid Effects of $17 \beta$-Estradiol on Dendritic Spines}

Treatment with $1.5,2$, or $3 \mu \mathrm{g} / \mathrm{kg}$ of $17 \beta$-estradiol increased dendritic spine density in the CA1 stratum radiatum within 40 min (Figure $3 \mathrm{a}$ and $\mathrm{b}$ ). However, dendritic spine density within the lacunosum-moleculare region of the CA1 did not significantly differ with treatment (Figure $4 \mathrm{a}$ and $\mathrm{b}$ ), nor did dendritic spine length in either subregion (Figures $3 c$ and $d$ and $4 \mathrm{c}$ and $\mathrm{d}$ ). Previous investigations reporting the genomic effects of estrogens on spine density have found significant increases with $17 \beta$-estradiol treatment in both the stratum radiatum and lacunosum-moleculare subregion of the hippocampus (Gould et al, 1990). One possible 
explanation for the lack of spine increases in the lacunosum-moleculare in the present study may lay with the timing and differences in hormone administration protocol after ovariectomy. Previous studies examining estrogen's genomic effects typically administered estradiol twice, at $\sim 3$ days and 5 days post-ovariectomy, and brain tissue extraction was done on day 7 (Gould et al, 1990), whereas we administered $17 \beta$-estradiol only once, $10-15$ days post-surgery and extracted tissues after $40 \mathrm{~min}$. Spine density was affected by the timing of estrogen administration following ovariectomy when treatment is delayed by weeks or months (McLaughlin et al, 2008; Smith et al, 2010). Although the timing of hormone administration used here was delayed only by 1 week compared with previous studies (ie, 3 days $v s 10$ days), this along with differences in hormone administration, may help to explain why we found no estrogen-mediated effects on dendritic spines in the lacunosum-moleculare.

The rapid increase in hippocampal spine density following $17 \beta$-estradiol treatment paralleled our estradiolmediated rapid improvements in learning and memory paradigms. These effects are also consistent with our previous work using ER $\alpha$ agonist PPT, which also rapidly increased CA1 dendritic spines in a manner that paralleled enhancements in performance on learning paradigms (Phan et al, 2011). Therefore, it is possible that estrogen-mediated increases in connections within brain structures relevant to learning and memory may lead to a facilitation of acquisition. Furthermore, since experience and learning itself changes dendritic spine density and shape (reviewed in $\mathrm{Yu}$ and $\mathrm{Zuo}, 2011$ ), it would be interesting to determine whether learning-driven and estradiol-driven dendritic spine changes interact in individuals receiving hormone treatment that are also tested in the learning paradigms. Interestingly, when the genomic effects of estrogens on synapse density was examined in rats that were or were not tested in the Morris water maze, estradiol benzoate increased spine density only in animals that did not undergo the learning paradigm (Frick et al, 2004).

These effects of estrogens on spine density are consistent with other studies that found estradiol rapidly increases synapses or spine density (MacLusky et al, 2005; Mukai et al, 2007; Murakami et al, 2006; Srivastava et al, 2008). Rapid estrogen-mediated increases in spine density are thought to occur through the activation of signaling cascades by estrogens, that then affect molecules important for actin cytoskeleton remodeling and dendritic spine formation (reviewed in Sanchez et al, 2012). In addition, estrogen's rapid effects on dendritic spines appear to be mediated through ER $\alpha$ in the hippocampus, as an ER $\alpha$ agonist can mimic estradiol's effects (Phan et al, 2011; Mukai et al, 2007; Murakami et al, 2006). The $\operatorname{ER} \beta$ agonist DPN, instead did not have an effect on spine density in the stratum radiatum or the lacunosum-moleculare (Phan et al, 2011; Mukai et al, 2007; Murakami et al, 2006), or decreased it at higher doses in the lacunosum-moleculare (Phan et al, 2011). In cultured cortical neurons, however, treatment with $\operatorname{ER} \beta$ agonist WAY-200070 increased dendritic spine density within 30-60 min (Srivastava et al, 2010). Thus, the involvement of $\operatorname{ER} \alpha$ and $\operatorname{ER} \beta$ for mediating estrogeninduced dendritic spine increases may be heterogeneous across different brain structures.

\section{CONCLUSIONS}

To our knowledge, this is the first report of $17 \beta$-estradiol improving learning within $40 \mathrm{~min}$ of administration. The timeframe used in this study corresponds to the timeframe for which rapid estrogen effects are reported on neuronal electrophysiology, cell signaling mechanisms, and other behaviors such as aggression and sexual behavior. The results were also obtained during a time in which memory is reported to be independent of transcription. Thus, our results provide support for the hypothesis that $17 \beta$-estradiol rapidly enhances learning and/or memory in a non-genomic manner. Moreover, we show that the same timeframe and the same doses of $17 \beta$-estradiol that produce improvements in learning tasks also rapidly increase dendritic spine density in the CA1 stratum radiatum. Together with our previous results, $17 \beta$-estradiol seems to rapidly improve performance in learning tasks and increase dendritic spine density via $\mathrm{ER} \alpha$ (Phan et al, 2011).

Rapid estrogen effects tend to be reported at higher dosages than are needed for their genomic effects, calling into question whether these rapid effects are biologically meaningful (reviewed in Woolley, 2007). Here, we show that dosages of $17 \beta$-estradiol equal to and lower than the dosage that produced proestrous-like high physiological levels of plasma estradiol in ovariectomized female rats (Scharfman et al, 2007) rapidly improves performance on learning tasks in ovariectomized female mice. Hence, these results suggest that $17 \beta$-estradiol is able to act rapidly to enhance learning and/or memory in natural systems. Within an animal, however, estrogens activate both rapid and genomic pathways, which likely affect one another. For example, rapid and genomic effects of estrogens produced additive effects to induce the estrogen-dependent lordosis behavior in female rats (Vasudevan and Pfaff, 2008; Vasudevan et al, 2005). Whether this is also true for learning and memory remains to be investigated. Effects of estrogens on learning and memory are complex, with reports of estrogen's effects ranging from impairing to improving learning and memory tasks (reviewed in Choleris et al, 2008). A better understanding of rapid and genomic effects within different neural structures, as well as activation through specific ERs, may explain these complex effects on learning and memory systems.

\section{ACKNOWLEDGEMENTS}

Grants supporting the writing of the paper: NSERC 400212 (EC) and NSERC 197293 (NJM), infrastructure Grant from CFI 046468 (EC), and JNA was the recipient of a NARSAD Young Investigator Award.

\section{DISCLOSURE}

The authors declare no conflict of interest.

\section{REFERENCES}

Bourtchuladze R, Frenguelli B, Blendy J, Cioffi D, Schutz G, Silva AJ (1994). Deficient long-term-memory in mice with a targeted mutation of the camp-responsive element-binding protein. Cell 79: 59-68. 
Broadbent NJ, Squire LR, Clark RE (2004). Spatial memory, recognition memory, and the hippocampus. Proc Natl Acad Sci USA 101: 14515-14520.

Charlier TD, Cornil CA, Ball GF, Balthazart J (2010). Diversity of mechanisms involved in aromatase regulation and estrogen action in the brain. Biochim Biophys Acta 1800: 1094-1105.

Choleris E, Clipperton AE, Phan A, Kavaliers M (2008). Estrogen receptor beta agonists in neurobehavioral investigations. Curr Opin Investig Drugs 9: 760-773.

Choleris E, Ogawa S, Kavaliers M, Gustafsson JA, Korach KS, Muglia LJ et al (2006). Involvement of estrogen receptor alpha, beta and oxytocin in social discrimination: a detailed behavioral analysis with knockout female mice. Genes Brain Behav 5: 528-539.

Clipperton Allen AE, Lee AW, Reyes A, Devidze N, Phan A, Pfaff DW et al (2011). Oxytocin, vasopressin and estrogen gene expression in relation to social recognition in female mice. Physiol Behav 105: 915-924.

Cornil CA, Dalla C, Papadopoulou-Daifoti Z, Baillien M, Balthazart J (2006). Estradiol rapidly activates male sexual behavior and affects brain monoamine levels in the quail brain. Behav Brain Res 166: 110-123.

Cross E, Roselli CE (1999). 17 beta-estradiol rapidly facilitates chemoinvestigation and mounting in castrated male rats. Am J Physiol Regul Integr Comp Physiol 276: R1346-R1350.

Da Silva WC, Bonini JS, Bevilaqua LRM, Medina JH, Izquierdo I, Cammarota M (2008). Inhibition of mRNA synthesis in the hippocampus impairs consolidation and reconsolidation of spatial memory. Hippocampus 18: 29-39.

Dere E, Huston JP, De Souza Silva MA (2007). The pharmacology, neuroanatomy and neurogenetics of one-trial object recognition in rodents. Neurosci Biobehav Rev 31: 673-704.

Fan L, Zhao Z, Orr PT, Chambers CH, Lewis MC, Frick KM (2010). Estradiol-induced object memory consolidation in middle-aged female mice requires dorsal hippocampal extracellular signalregulated kinase and phosphatidylinositol 3-kinase activation. J Neurosci 30: 4390-4400.

Fernandez SM, Lewis MC, Pechenino AS, Harburger LL, Orr PT, Gresack JE et al (2008). Estradiol-induced enhancement of object memory consolidation involves hippocampal extracellular signal-regulated kinase activation and membrane-bound estrogen receptors. J Neurosci 28: 8660-8667.

Foy MR, Xu J, Xie X, Brinton RD, Thompson RF, Berger TW (1999). 17 beta-estradiol enhances NMDA receptor-mediated EPSPs and long-term potentiation. J Neurophysiol 81: 925-929.

Frick KM, Fernandez SM, Bennett JC, Prange-Kiel J, MacLusky NJ, Leranth C (2004). Behavioral training interferes with the ability of gonadal hormones to increase CA1 spine synapse density in ovariectomized female rats. Eur J Neurosci 19: 3026-3032.

Gabor CS, Lymer J, Systerova U, Phan A, Choleris E (2011). Rapid effects of estrogen receptor GPER/GPR30 agonist G-1 on learning and memory in female mice. Abstr Soc Neurosci 41: 72803.

Gould E, Woolley CS, Frankfurt M, McEwen BS (1990). Gonadalsteroids regulate dendritic spine density in hippocampal pyramidal cells in adulthood. J Neurosci 10: 1286-1291.

Gresack JE, Frick KM (2006). Post-training estrogen enhances spatial and object memory consolidation in female mice. Pharmacol Biochem Behav 84: 112-119.

Haisenleder DJ, Schoenfelder AH, Marcinko ES, Geddis LM, Marshall JC (2011). Estimation of estradiol in mouse serum samples: evaluation of commercial estradiol immunoassays. Endocrinology 152: 4443-4447.

Harris HA, Chennathukuzhi VM, Zhang X, Mekonnen B, Jelinsky SA, Schelling SH et al (2008). Development of an early biomarker for the ovarian liability of selective estrogen receptor modulators in rats. J Steroid Biochem Mol Biol 112: 40-46.
Iizuka S, Ishige A, Komatsu Y, Matsumiya T, Inazu M, Takeda H (1998). Effects of Toki-shakuyaku-san on electric footshock stress in ovariectomized mice. Methods Find Exp Clin Pharmacol 20: 39-46.

Inagaki T, Gautreaux C, Luine V (2010). Acute estrogen treatment facilitates recognition memory consolidation and alters monoamine levels in memory-related brain areas. Horm Behav 58: 415-426.

Kelly MJ, Ronnekleiv OK (2009). Control of CNS neuronal excitability by estrogens via membrane-initiated signaling. $\mathrm{Mol}$ Cell Endocrinol 308: 17-25.

Lewis MC, Kerr KM, Orr PT, Frick KM (2008). Estradiol-induced enhancement of object memory consolidation involves NMDA receptors and protein kinase $\mathrm{A}$ in the dorsal hippocampus of female C57BL. Behav Neurosci 122: 716-721.

Luine VN, Jacome LF, Maclusky NJ (2003). Rapid enhancement of visual and place memory by estrogens in rats. Endocrinology 144: 2836-2844.

MacLusky NJ, Luine VN, Hajszan T, Leranth C (2005). The 17 alpha and 17 beta isomers of estradiol both induce rapid spine synapse formation in the CA1 hippocampal subfield of ovariectomized female rats. Endocrinology 146: 287-293.

Malinow R, Schulman H, Tsien RW (1989). Inhibition of postsynaptic PKC or CAMKII blocks induction but not expression of LTP. Science 245: 862-866.

McLaughlin KJ, Bimonte-Nelson H, Neisewander JL, Conrad CD (2008). Assessment of estradiol influence on spatial tasks and hippocampal CA1 spines: evidence that the duration of hormone deprivation after ovariectomy compromises 17 beta-estradiol effectiveness in altering CA1 spines. Horm Behav 54: 386-395.

Mukai H, Tsurugizawa T, Murakami G, Kominami S, Ishii H, Ogiue-Ikeda M et al (2007). Rapid modulation of long-term depression and spinogenesis via synaptic estrogen receptors in hippocampal principal neurons. J Neurochem 100: 950-967.

Murakami G, Tsurugizawa T, Hatanaka Y, Komatsuzaki Y, Tanabe $\mathrm{N}$, Mukai $\mathrm{H}$ et al (2006). Comparison between basal and apical dendritic spines in estrogen-induced rapid spinogenesis of CA1 principal neurons in the adult hippocampus. Biochem Biophys Res Commun 351: 553-558.

Nguyen PV, Abel T, Kandel ER (1994). Requirement of a critical period of transcription for induction of a late-phase of Ltp. Science 265: 1104-1107.

Nilsson S, Makela S, Treuter E, Tujague M, Thomsen J, Andersson $\mathrm{G}$ et al (2001). Mechanisms of estrogen action. Physiol Rev 81: 1535-1565.

Padilla-Banks E, Jefferson WN, Newbold RR (2001). The immature mouse is a suitable model for detection of estrogenicity in the uterotropic bioassay. Environ Health Perspect 109: 821-826.

Peano BJ, Crabtree JS, Komm BS, Winneker RC, Harris HA (2009). Effects of various selective estrogen receptor modulators with or without conjugated estrogens on mouse mammary gland. Endocrinology 150: 1897-1903.

Petrulis A (2009). Neural mechanisms of individual and sexual recognition in Syrian hamsters (Mesocricetus auratus). Behav Brain Res 200: 260-267.

Phan A, Lancaster KE, Armstrong JN, MacLusky NJ, Choleris E (2011). Rapid effects of estrogen receptor $\alpha$ and $\beta$ selective agonists on learning and dendritic spines in female mice. Endocrinology 152: 1492-1502.

Sanchez AM, Flamini MI, Polak K, Palla G, Spina S, Mannella P et al (2012). Actin cytoskeleton remodelling by sex steroids in neurones. J Neuroendocrinol 24: 195-201.

Sarkar SN, Huang R, Logan SM, Yi KD, Dillon GH, Simpkins JW (2008). Estrogens directly potentiate neuronal L-type Ca2+ channels. Proc Natl Acad Sci USA 105: 15148-15153.

Sawai T, Bernier F, Fukushima T, Hashimoto T, Ogura H, Nishizawa Y (2002). Estrogen induces a rapid increase of 
calcium-calmodulin-dependent protein kinase II activity in the hippocampus. Brain Res 950: 308-311.

Scharfman HE, Hintz TM, Gomez J, Stormes KA, Barouk S, Malthankar-Phatak GH et al (2007). Changes in hippocampal function of ovariectomized rats after sequential low doses of estradiol to simulate the preovulatory estrogen surge. Eur $J$ Neurosci 26: 2595-2612.

Smejkalova T, Woolley CS (2010). Estradiol acutely potentiates hippocampal excitatory synaptic transmission through a presynaptic mechanism. J Neurosci 30: 16137-16148.

Smith CC, Vedder LC, Nelson AR, Bredemann TM, McMahon LL (2010). Duration of estrogen deprivation, not chronological age, prevents estrogen's ability to enhance hippocampal synaptic physiology. Proc Natl Acad Sci USA 107: 19543-19548.

Srivastava DP, Woolfrey K, Jones KA, Shum CY, Lash LL, Swanson GT et al (2008). Rapid enhancement of two-step wiring plasticity by estrogen and NMDA receptor activity. Proc Natl Acad Sci USA 105: $14650-14655$.

Srivastava DP, Woolfrey KM, Liu F, Brandon NJ, Penzes P (2010). Estrogen receptor beta activity modulates synaptic signaling and structure. J Neurosci 30: 13454-13460.

Thomas GM, Huganir RL (2004). MAPK cascade signaling and synaptic plasticity. Nat Rev Neurosci 5: 173-183.

Trainor BC, Finy MS, Nelson RJ (2008). Rapid effects of estradiol on male aggression depend on photoperiod in reproductively non-responsive mice. Horm Behav 53: 192-199.

Vasudevan N, Kow LM, Pfaff D (2005). Integration of steroid hormone initiated membrane action to genomic function in the brain. Steroids 70: 388-396.
Vasudevan N, Pfaff DW (2008). Non-genomic actions of estrogens and their interaction with genomic actions in the brain. Front Neuroendocrinol 29: 238-257.

Walf AA, Koonce CJ, Frye CA (2008). Estradiol or diarylpropionitrile administration to wild type, but not estrogen receptor beta knockout, mice enhances performance in the object recognition and object placement tasks. Neurobiol Learn Mem 89: 513-521.

Woolley CS (2007). Acute effects of estrogen on neuronal physiology. Annu Rev Pharmacol Toxicol 47: 657-680.

Wu TW, Wang JM, Chen S, Brinton RD (2005). 17 beta-Estradiol induced $\mathrm{Ca} 2+$ influx via L-type calcium channels activates the Src/ERK. Neuroscience 135: 59-72.

Yu X, Zuo Y (2011). Spine plasticity in the motor cortex. Curr Opin Neurobiol 21: 169-174.

Zadran S, Qin QY, Bi XN, Zadran H, Kim Y, Foy MR et al (2009). 17-beta-Estradiol increases neuronal excitability through MAP kinase-induced calpain activation. Proc Natl Acad Sci USA 106: 21936-21941.

Zhao L, Chen S, Wang JM, Brinton RD (2005). 17 beta-estradiol induces $\mathrm{Ca} 2+$ influx, dendritic and nuclear $\mathrm{Ca} 2+$ rise and subsequent cyclic amp response element-binding protein activation in hippocampal neurons: a potential initiation mechanism for estrogen neurotrophism. Neuroscience 132: 299-311.

Zhao LZ, Brinton RD (2007). Estrogen receptor alpha and beta differentially regulate intracellular $\mathrm{Ca} 2+$ dynamics leading to ERK phosphorylation and estrogen neuroprotection in hippocampal neurons. Brain Res 1172: 48-59. 